\title{
Applied economic model development algorithm for electronics company
}

\author{
I. Mikhailov, ${ }^{1, *}$ \\ ${ }^{1}$ Russian Scientific Research Institute "Elektronstandart”, Saint Petersburg, Russia
}

\begin{abstract}
The purpose of this paper is to report about received experience in the field of creating the actual methods and algorithms that help to simplify development of applied decision support systems. It reports about an algorithm, which is a result of two years research and have more than one-year practical verification. In a case of testing electronic components, the time of the contract conclusion is crucial point to make the greatest managerial mistake. At this stage, it is difficult to achieve a realistic assessment of time-limit and of wage-fund for future work. The creation of estimating model is possible way to solve this problem. In the article is represented an algorithm for creation of those models. The algorithm is based on example of the analytical model development that serves for amount of work estimation. The paper lists the algorithm's stages and explains their meanings with participants' goals. The implementation of the algorithm have made possible twofold acceleration of these models development and fulfilment of management's requirements. The resulting models have made a significant economic effect. A new set of tasks was identified to be further theoretical study.
\end{abstract}

\section{Introduction}

Electronic components serve as the basis for electronic systems and in case of the need to create devices for special applications it must pass a series of tests to confirm its compliance with the requirements for this kind of products. Due to the strong growth of modernization projects number in the Russian militaryindustrial complex and an increase in the number of newly developed devices, as well as tightening their requirements, more and more complicated test conditions, during the last years re-emerged and grew up strong demand for the methods and algorithms those could help to simplify an application development in the field of applied decision support systems. The main goal is to cover the lack of justification and give an evaluation for making administrative solutions more efficiency or at least ease the process of their search.

The probability of making a wrong management decision depends on the degree of conditions uncertainty. The extent of the negative effects rises over time and has continuous increase the longer it is fixed and supported in the course of business. At the intersection of these two critical moments of greatest probability of making a wrong decision and the toughest possible consequences in a case of testing electronic components is the time of the contract conclusion. The most unpredictable and difficult tasks at this stage are future work costs definition, as well as duration justification. To perform the task of determining required time with using native methods, there is an alternative to the following extremes: overstatement of the projected period will lead to the impossibility of finding an agreement with the customer and the loss of a potential client, and when specifying a too short time interval, the danger lies in the inability to carry it out, which can lead to a significant leadership responsibility, especially in the case of a contract in the interest of the state defense ministry.

At the contract conclusion time is difficult to achieve a realistic assessment of time-limit due to the presence of not only the established norms of terms (standard documentation requirements, the pure real time needed to perform machine measurement), but also less predictable components: the duration of the development and establishment of a special measuring equipment, the ability to buy its indispensable equipment, the duration of their delivery, terms of writing special measuring software. It is important to emphasize that these variables must be applied to evaluation amount of time for each incoming product, while in one contract, often indicates the wide range of part types: the former is already partly on the tests and do not require repreparatory work.

The problem of rational contract price definition is as well not trivial. Cost of the work is formed by a number of terms that depend on two main components: the cost of the components - printed circuit boards, contact devices, as well as the wage bill. Because the contract is concluded and price will be fixed before the actual start of work and receiving of advance payment, by the time of the purchase the most part of foreign components, due to changes in currency exchange rates may rise unpredictable in price, in depend on the political and general economic conditions. Justified estimation of wage bill size is also difficult due to the prevailing structure of work, which largely consists of engineering research, but not of handling and service directly involved measuring and test equipment.

Possible way to solution the above-mentioned complexity lies through creating a model that allows assessing the amount of work for the planned task. That way it is possible to reduce the degree of uncertainty in determining the cost and terms of a projected contract. Therefore, for the construction of such models was 
formulated the sequence of work - in the title of this article mentioned algorithm that was successfully estimated through developing and implementing two modules of information support.

\section{Methodological foundation of the algorithm construction}

In last years was adopted a series of more than twenty documents, similar to the requirements established by International Electrotechnical Commission [1] in the field of testing of electronic components at the state level standard of the Russian Federation. Meanwhile the current approach to the assessment and valuation amount of labor significantly outdated [2]-[5] and has not been modified since the mid-90s. Since that time, much has changed: not only listed above testing requirements and used for this purpose equipment, but also the whole range of tested products. Because of the transition to a market economy the enterprises management conditions have shifted radically, as well as in connection with a wide spread of information technology was adjusted the principle of collecting, processing and storage of information required to manage the company.

Described in the standards and published in the end of the nineties years XX century approach inherits the features of a planned economy and universalistic attitude to management [6] and tries to establish an interbranch, cross-sectoral, general standards for all kinds of businesses. Shown in this article way of thinking and methodologically it generated algorithm is premised on the dialectical opposites [7] - the existing level of individual business development and calls for the integration of business processes specific test centers and laboratories. It should be noted that this approach to consider "specific cases" is gaining more and more widely accepted in all areas of modern economic and managerial science [8]-[11]. In addition for establishing the algorithm were used the principles laid down in the state standards of the Russian Federation [12], [13], the general methods of scientific research, typical of logical positivism and the heritage of Ernst Mach philosophy of science [14].

\section{The algorithm for creating the analytical model amount of work estimation}

\section{Step 0: Managerial purposes understanding}

This step is not an actual part of the development algorithm, but we felt it necessary to remind that before the start of quite expensive and not always simple works toward model creation it is worth to identify the existing problems and arrange the tasks list that a system must be able to accomplish at the final stage. Only if these purposes cannot be achieved in a simpler way, we may recommend to create the model using this algorithm.

\section{Step 1: Business process scheme drafting}

The first step in creating of the analytical model is drafting of "process flow" and "object transition" IDEF3 diagrams [15] for the business processes already existing in the organization. Using the notation IDEF0 [16], as expected, it turned out to be arduous and created difficulty interpreting at complication of the model structure. At this stage along with the business analysts must be joined line managers, who are responsible for reviewed organization divisions.

As a further development of this stage, it seems appropriate to recommend an assessment of the potential benefits of replacing used IDEF3 approach to active developing [17]-[20] BPMN notation, which is due to greater visibility must be well understood not only by business analysts and attracted engineers as experts, but also by all levels of management.

\section{Step 2: Operations lists filling}

The second step is reconciliation with engineers-experts, who daily implement instruments on labor intensity. Existing documents and compiled at the first stage in conjunction with line managers business process diagrams must be discussed. It is figured out, that even linear managers which are nearest to real operating processes often ignore or even doesn't know about some important obstacles that could occur during the everyday's work. Therefore, list of operations that was outlined at the first stage together with the managers must be checked to identify unaccounted, unknown or considered by management as minor works. In some cases, these hidden works can be critical in future for the process flow control. It is required to set the execution time for each operation and the conditions under which it is performed, based on the evidence of experts, to have an instrument to branch business process in a different way if needed.

The involvement of staff in this step is justified from a number of reasons: professional with extensive practical experience is an expert in his field and the best source of information. Second, it ensures the absence of opposition from the ordinary performers, no disturbance at the workplaces, the openness and clarity of procedures carried out - which does not allow developing a conflict of blue- and white-collar workers. This assists achieving the involvement of staff - one of the requirements of modern view on efficient management [21], and helps to realize the interviewed experts needs of high estimation and self-actualization [22], [23] - that can serve as an indirect non-material encouragement and recognition on the part of management. The main actors of this stage along with the business analysts are engineers-experts.

\section{Step 3: Gathered data verification}

The third step is verification of in the previous stage obtained from the experts' knowledge. This phase aims to perform two tests: the logical and empirical. The first is to eliminate logical and technology contradictions in 
reconciling the recorded responses through to a reconsultation or referral to an independent third party. Its result is the business process scheme, including the sequence of factually performed operations, consistent and clear to management.

The second, empirical test is needed to clarify by performers' posed time-standards. Obviously, the number of workers will tend to inflate their estimation of the time required to perform discussed task. Such a reconciliation of the data can be carried out through statistical accounting of data for previous periods. Relatively simple marks about needed periods of time for operations implementation, collected as a "black boxes", without any kind of their nature explanation, at this stage can found perhaps the only justifiable practical application. The leading person at the third stage is a business analyst, which if necessary, can engage consultants to address the issues with respect to the logical or temporal mismatch identified in the available data.

\section{Step 4: System complexity determination}

The fourth step is to choose a rational number of dimensions involved as multipliers in the system of polynomial functions necessary to calculate amount of work.

The number of dimensions for each work considered separately influences on results reliability and depends on accepted by senior management degree of abstraction. The upper limit of the relationship kinds and business logic system complexity should be consistent with the business informatics experts, whom going to be involved at a later stage for the software implementation of the model. Consequently, fourth stage participants are business analysts, senior management and business informatics experts.

It is important to stress despite the fact that the algorithm realization experience showed that the information obtained from the experts, often in their complexity and number greatly exceeds the amount of details required to implement management's needs to value prediction. However, it should be borne in mind that at this stage a case of special requirements extension on the part of senior management is not excluded at all. In case of their appearance, it would be necessary to get more details of working processes applied to the selected organizational unit, which could lead to a new iteration of the algorithm.

\section{Step 5: Program implementation}

The fifth stage contains the program implementation of the compiled information complex, which usually consists of united relationships between gathered process parameters, based common system of polynomial equations. Actual software developing project can be implemented using a variety of approaches [24]-[27], based on the use of general-purpose programming languages, databases, distributed web interfaces. The main participants at this stage are business informatics experts and programmers.

\section{The algorithm implementation's results}

The algorithm was tested twice to create analytical models for calculating the cost and amount of works carried out by Test Center of Russian Scientific Research Institute "Elektronstandart" (RNIIES) and electronic components assembly department of RNIIES.

The applying of the algorithm have made possible the creation of these models, as well as more than twofold acceleration of their development time, compared with the projected period, calculated by consulting companies for introduction of the DSS and ERP-systems. The result of the integration into business practices was raising the methodological reliability of the labor amount estimation, and therefore, the accuracy of prediction of the organization labor costs, nearly $30 \%$ increase in the accuracy of the timing of planned activities. The calculations term for the contract conditions dropped from ten to one day, the influence of the human factor was reduced, arbitrary interpretations in assessing the complexity of the work was excluded.

\section{Conclusion}

This paper has introduced the five stage algorithm to development of applied economic model that was successfully implemented in electronic company. We assume that the sphere of usage for this algorithm could be expanded towards other branches if for them will remain true the main condition based on using of high skilled workers' experience as company's intellectual capital to improve management efficiency.

Pilot testing of the algorithm has identified a new set of tasks to be further theoretical study. The question was raised feasibility of expanding the algorithm by adding the simulation components [28] that extends the functionality of the analytical model through including of production planning subsystem. Besides, the use of the algorithm provides a basis to initiation of an analysis and a classification of works that must lead to rational choice between analytical, simulation and hybrid models most appropriate for selected kind of investigated working activities. Inspired by the perspectives of further increasing model's functionality, we plan to consider methods to implement neural nets for forecasting of planned works and costs optimization to our algorithm in the future work.

\section{References}

1. Series of Russian national standards GOST R IEC 60068; GOST R IEC 61587; GOST R IEC 61508; GOST R IEC 60906

2. Resolution of the Russian Federation Ministry of Labour, 56 (1995) 
3. Resolution of the Russian Federation Ministry of Labour, 72 (1994)

4. Resolution of the USSR Ministry of Labour, 69 (1991)

5. Resolution of the USSR Ministry of Labour, 80 (1991)

6. A. Bogdanov, Essays in Tektology: The General Science of Organization (Intersystems Publications, Seaside, CA, 1980)

7. K. Hartmann, Hegels Logik (De Gruyter Publ., Berlin 1999)

8. E.H. Nathanael, B. Hendradjaya, W. Danar Sunindyo, ICEEI, 427-432 (2015). DOI: 10.1109/ICEEI.2015.7352539.

9. I.A. Brusakova, Proc. IV Forum Strategic Partnership of Universities and Enterprises of $\mathrm{Hi}$ Tech Branches, 77-79 (2015). DOI: 10.1109/IVForum.2015.7388260.

10. A. Esmaeilzadeh, A.A. Taleizadeh, Journal of Industrial Engineering International, 12, 1, 119-135. DOI: $10.1007 / \mathrm{s} 40092-015-0135-5$.

11. M.A. Kosuhina, I.A. Brusakova, Proc. XVIII International Conference on Soft Computing and Measurements (SCM), 291-293 (2015). DOI: 10.1109/SCM.2015.7190487.

12. Series of Russian national standards GOST R ISO 9000 .

13. Russian national standard GOST R 56407-2015

14. E. Mach, Knowledge and Error: Sketches on the Psychology of Enquiry (1976)

15. R. Mayer, M. Painter, C. Menzel, B. Perakath, P. deWitte, T. Blinn, IDEF3 Process Description Capture Method Report, (Knowledge Based Systems Publ., 1995)

16. National Institute of Standards and Technology (1993)
17. Ching-Hong Tsai, How-Jen Luo, Feng-Jian Wang, Proc. 11th IEEE International Workshop on Future Trends of Distributed Computing Systems (2007). DOI: 10.1109/FTDCS.2007.17.

18. R. Braun, Proc. IEEE 17th Conference on Business Informatics (CBI) (2015). DOI: 10.1109/CBI.2015.41.

19. S. Yamasathien, Proc. Fourth International Conference on Digital Information and Communication Technology and it's Applications (DICTAP) (2014). DOI: 10.1109/DICTAP.2014.6821684.

20. M. Chinosi, A. Trombetta, IEEE Conference on Commerce and Enterprise Computing, (2009). DOI: 10.1109/CEC.2009.48.

21. Toyota Code of Conduct, Toyota motor corporation Publ. (2006)

22. A.H. Maslow, Psychological Review, 50(4), 370396 (1943)

23. A.H. Maslow, Motivation and personality, (Harper \& Row Publ., 1954)

24. J.O. Long, ITIL 2011 At a Glance, (Springer New York Publ., 2012). DOI: 10.1007/978-1-4614-38977.

25. A Guide to the Project Management Body of Knowledge (PMBOK Guide), (Project Management Institute Publ., 2013)

26. T.A. Khudyakova, Proc. of the International Congress on Interdisciplinary Behavior and Social Science, 292-294 (2015)

27. K. Beck, Extreme Programming Explained: Embrace Change, (Addison-Wesley Professional Publ., 1999)

28. D. Katalevsky, The Basics of Simulations and System Analysis in Management (Delo Publ., Moscow, 2015) 